\title{
Educação municipal e efetivação do direito à educação*
}

Dirce Nei Teixeira de Freitas"*

Maria Dilnéia Espíndola Fernandes"'

\section{Resumo}

Os avanços brasileiros na efetivação do direito público subjetivo à educação têm sido obtidos num contexto de aumento da participação municipal. Mas, os desafios ainda são complexos, sendo que a educação municipal, múltipla e díspar, tem responsabilidades crescentes na extensão da obrigatoriedade escolar. Assim, o texto traz uma análise de como seis municípios sul-mato-grossenses têm se organizado para efetivar o direito à educação, privilegiando a dimensão legislativa e a administração. Utiliza como fontes documentos, informações obtidas junto a Secretarias e Conselhos Municipais de Educação por meio de questionários, índices e indicadores disponibilizados na Internet por órgãos especializados. Os dados mostraram ser escassa a contribuição legislativa municipal para o estabelecimento de políticas locais pró-efetivação do direito à educação, e ainda, para sinalizar a gestão que se mostrou fragmentária, com baixo grau de inventividade e necessitada de um sistema de proteção articulado.

Palavras-chave: Ensino fundamental. Política educacional. Gestão educacional. Educação municipal.

\section{Municipal education and the establishment of the right to education Abstract}

The Brazilian advances in the realization of the subjective public right to education have been achieved in a context of increasing municipal participation. But the challenges are still complex. Municipal education -multiple and disparate- has increasing responsibilities in the extension of compulsory education. Thus, this paper

\footnotetext{
Baseado parcialmente no texto "Gestão local e efetivação do direito à educação", publicado nos anais da 31 ${ }^{\text {a }}$ Reunião Anual da ANPEd, Caxambu, 2008.

** Doutora em Educação, PPGEdu/UFGD/FACED. E-mail: dircenei@terra.com.br

".. Doutora em Educação, PPGEdu/UFMS/DED. E-mail: mdilneia@uol.com.br
} 
presents an analysis of how six municipalities in the state of Mato Grosso do Sul have been organized to put the right to education into effect, focusing on the administration and legislative dimension. The sources for the analysis are documents, information obtained by Secretaries of Education and members of Municipal Councils of Education through questionnaires, indexes and indicators available on the Internet by specialized organs. The data showed only little contribution to the municipal legislative establishment of local political pro-realization of the right to education, and also signal to management which proved fragmentary, with a low degree of inventiveness and in need of an articulated system of protection.

Keywords: Elementary school. Educational policy. Educational management. Municipal education.

\section{Educación municipal y realización del derecho a la educación}

Resumen:

Los avances brasileños en la tarea de hacer efectivo el derecho público subjetivo a la educación se han alcanzado en un contexto de aumento de la participación municipal. Sin embargo, los desafíos aún son complejos. La educación municipal, múltiple y desigual, tiene responsabilidades crecientes en la extensión de la obligatoriedad escolar. Así, el texto presenta un análisis de como seis municipios de Mato Grosso do Sul se han organizado para efectuar el derecho a la educación, privilegiando la dimensión legislativa y la administración. Se han utilizado como fuentes documentos, informaciones obtenidas junto a Direcciones y Consejos Municipales de Educación mediante cuestionarios, índices e indicadores disponibles en Internet por órganos especializados. Los datos muestran que es escasa la contribución legislativa municipal para el establecimiento de políticas locales a favor de la efectivación del derecho a la educación, e incluso, para señalar la gestión que se mostró fragmentaria, con bajo grado de inventividad y necesitada de un sistema de protección articulado.

Palabras clave: Enseñanza fundamental. Política educacional. Gestión educacional. Educación municipal.

No decurso da primeira década deste século, deu-se por universalizado no Brasil o acesso ao ensino obrigatório, tendo alguns de seus indicadores apresentado meIhora, ainda que os ganhos na qualidade do desempenho cognitivo dos alunos não tenham sido expressivos. Os avanços foram obtidos num contexto de aumento da participação municipal na prestação educacional, inclusive por meio da extensão do ensino fundamental à população de seis anos de idade.

Nos últimos anos, os desafios à educação municipal foram dimensionados com a projeção de metas de melhoria de qualidade (BRASIL, 2007a) e de ampliação da obrigatoriedade da prestação estendida primeiro à população de seis anos de idade 
- Leis $n^{\circ}$. 11.114 (BRASIL, 2005) e $n^{\circ}$. 11.274 (BRASIL, 2006b) -, e depois à de quatro a seis anos de idade - Emenda Constitucional (EC) nº. 59 (BRASIL, 2009). Assim, ao Município cabe, atualmente, a responsabilidade principal da oferta de 11 dos 14 anos de escolarização obrigatória fixada constitucionalmente. Cresce, portanto, a importância da política e da gestão educacionais nos municípios brasileiros.

Com isso, a pesquisa educacional tem se voltado para a investigação da efetivação da educação municipal. Esta é sabidamente múltipla e díspar, qualquer que seja a unidade de análise: estadual, regional, nacional. Representa, assim, um importante desafio à pesquisa na área.

Basicamente, a investigação das redes escolares municipais se justifica pela importância do município no federalismo brasileiro com a sua instituição - pela Constituição Federal de 1988 (BRASIL, 1988) -, como ente federativo, com responsabilidades e deveres próprios, em um modelo de relações que expressa, por um lado, a interdependência entre as esferas de governo e, por outro lado, a autonomia para intervenções e regulações locais (ABRUCIO, 2006; SOUZA, 2006). Esse processo assume dimensão considerável, na medida em que a repartição constitucional da carga tributária trouxe significativo ganho para os municipios (ANDRADE, 2004). Acrescenta-se a isso, entre outras coisas, o fato de que o planejamento nacional e internacional da educação colocou novos desafios e responsabilidades à esfera local.

Atentando para essa tendência, investigamos como municípios sul-mato-grossenses têm se organizado para efetivar o ensino fundamental. 0 campo de observação foi composto de seis redes escolares localizadas em três regiões do estado: Oeste, Centro e Sul. Deixaram de serem observadas redes escolares das regiões Norte e Leste, devido à falta de financiamento da pesquisa, fator que restringiu também a composição do conjunto observado. Embora com essas limitações, chegamos a um conjunto de redes de diferentes portes, condições e potencialidades, que nos permitiram investigar configurações particulares num universo de 78 redes existentes que, em conjunto, respondiam, no ano de 2007, por $40 \%$ do ensino fundamental municipal do estado.

0 ângulo privilegiado na pesquisa foi o do uso, pelos municípios, das suas prerrogativas legais para construir a sua política consoante ao novo pacto federativo estabelecido com a Constituição Federal (BRASIL, 1988) e ao estatuto do direito público subjetivo à educação reservado nessa Carta ao ensino fundamental.

Basicamente, buscamos saber se a política e gestão da educação municipal vêm se efetivando numa esfera de autonomia relativa, ou se efetivando exclusivamente pelas regulações da esfera central do pais, ou, ainda, numa combinação entre estas duas situações. $E_{1}$ ainda, o que isso representa no tocante à efetivação do direito de todos ao ensino fundamental. 
Para isso, investigamos a atuação municipal tanto na esfera legislativa, mediante elaboração de dispositivos de sua competência, como na esfera administrativa, por meio das iniciativas de regulamentação do Conselho Municipal de Educação e da liderança executiva da Secretaria de Educação.

\section{Proteção jurídica e efetivação do direito à educação no Brasil após 1988}

A configuração do direito à educação na Constituição Federal (BRASIL, 1988) expressou o momento histórico de redemocratização da sociedade brasileira, que demandou dos constituintes compromissos com o alargamento dos direitos sociais para o conjunto da população. Porém, não de forma suficientemente ampla.

Os direitos educacionais receberam proteção jurídica diferenciada no ordenamento legal brasileiro (BRASIL, 1988), reservando-se ao ensino fundamental o instituto do "direito público subjetivo" (DUARTE, 2004, 2006, 2007).

A importância desse instituto está no fato de que ele, conforme explica Duarte (2006, p. 149-150), "[...] permite a proteção da dimensão subjetiva de um direito fundamental de natureza social [...]" no "[...] contexto de uma Constituição afinada com os padrões do Estado de direito social e democrático". Com isso, esse ensino passou a contar com três mecanismos imprescindiveis à sua efetivação, a saber:

- a obrigatoriedade ao Estado, à sociedade e aos indivíduos (HORTA, 1998);

- a gratuidade relativa a gastos diretos para acesso e permanência (VIEIRA, 2004);

- a exigibilidade instrumentada juridicamente (OLIVEIRA, 1995; DIGIÁCOMO, 2004).

Com a proteção do direito público subjetivo, o ensino fundamental se tornou prioritário no "sistema de garantias" do direito à educação (MARQUES, 2004). 0 ensino, cuja duração mínima era de oito anos, foi ampliada para nove anos, e estendido à população de seis anos de idade, com as Leis no. 11.114 (BRASIL, 2005) e no. 11.274 (BRASIL, 2006b).

Duarte (2006) observa que, entretanto, a adequação do direito público subjetivo para exigir do Estado o cumprimento das políticas públicas constitucionalmente delineadas, "objeto precípuo dos direitos sociais", tem sido objeto de polêmicas, com o que o êxito de ações judiciais pró-efetivação do direito à educação tem sido obstaculizado.

Contudo, a proteção "desbalanceada" conferida às etapas e modalidades da educação básica no Brasil (educação infantil, ensino fundamental, ensino médio, educação especial e educação de jovens e adultos), segundo Duarte (2007), não elimina 0 fato de que todas elas são alcançadas pelo "estatuto jurídico comum aos direitos sociais", possibilitando o questionamento judicial de violações. Essa tem sido uma das forças propulsoras da efetivação do direito à educação no país. 
A preocupação com a efetivação desse direito no Brasil teve também como força propulsora a afirmação da educação como um direito humano no contexto internacional (MONTEIRO, 2003a, 2003b, 2006; NACIONES UNIDAS, 2004), num tempo em que se tem

[...] assistido a um espraiamento das camadas de gestão governamental dentro e através das fronteiras políticas. Novas instituições internacionais e transnacionais têm vinculado Estados soberanos e transformado a soberania num exercicio compartilhado do poder (HELD; McGREW, 2001, p. 31).

Nesse contexto, iniciativas de coordenação mundial da educação - por meio de conferências, fóruns, reuniões de cúpulas e outras - colocaram, mais intensamente a partir do ingresso nos anos 1990, importantes desafios educacionais para paises populosos e com importantes déficits de escolarização como é o caso do Brasil.

Entre tais desafios está o da universalização da "educação básica" com qualidade, que foi objeto dos acordos estabelecidos nas Conferências de Educação para Todos (CONFERÊNCIA NACIONAL..., 1994)'.

Entretanto, Torres (2001) ressalta que tais acordos foram firmados sem base consensual sobre o que se estava a denominar educação básica. Assim, cada país consignatário dos acordos compreenderia e materializaria de forma diferenciada a tarefa de escolarização a ela correspondente.

O Brasil instituiu a educação básica como primeiro nível de escolarização destinado à faixa etária até dezessete anos e, ainda, extensiva aos não escolarizados em idade regular - Lei. no. 9.394/1996 (apud BRASIL, 2001). Contudo, a obrigatoriedade foi mantida somente para o ensino fundamental, com a correspondente proteção pública a ele direcionada prioritariamente.

No nosso entendimento, isso se deu menos por força do direito internacional do que de condicionantes internos. Corroboram nesse sentido, as ponderações de Tomasevski $(2006$, p. 63) de que

Existem muitas e detalhadas normas internacionais regulando cada aspecto do direito à educação; no entanto, as leis internacionais de direitos humanos são auto-reguláveis pelos governos nacionais e podem tanto refletir como substituir o compromisso assumido por esses governos.

\footnotetext{
1 Sobre orientações para o planejamento educacional decorrente das Conferências Mundiais de Educação para Todos, ver Unesco ([199?]). Para uma avaliação do planejamento educacional decorrente das Conferências Mundiais de Educação para Todos, ver Torres (2001). Sobre os encaminhamentos das Conferências Mundiais de Educação para Todos no Brasil ver Conferência Nacional de Educação para Todos (1994).
} 
Inexistindo autoridade supranacional que imponha e faça valer os direitos humanos, a "pressão nacional" seria, para Tomasevski (2006), a via para exigir-se dos governos o cumprimento dos compromissos assumidos pelos seus países.

No caso brasileiro, as aspirações - não sem conflitos - das elites econômicas, políticas, intelectuais e burocráticas de que o país empreendesse, com prioridade, esforços na busca de maior inserção no contexto internacional concorreram para que a agenda globalmente estruturada para a educação, de que fala Dale (2001) fosse mais amplamente acolhida nos últimos anos.

Mas, não há dúvida de que a propagação do discurso dos direitos humanos na sua versão após Viena 1993 (CONFERÊNCIA MUNDIAL..., 1993) tem influenciado decisões educacionais no pais, assim como sinalizações da comunidade internacional na fixação de metas e na propagação de indicadores de qualidade.

São ilustrativos o marco das metas do Milênio da Organização das Nações Unidas (NAÇÕES UNIDAS, 2000) e iniciativas de comparações internacionais sob liderança da Organização para Cooperação e Desenvolvimento Econômico (OCDE) (OECD, 2009). São reflexos disso a mobilização de setores da sociedade que concorreram para a instituição do Plano de Metas Compromisso Todos pela Educação, por meio do Decreto nº 6.094 (BRASIL, 2007a) no qual a qualificação do ensino fundamental é priorizada. Também a ampliação da obrigatoriedade de escolarização de nove para catorze anos de duração, para a faixa etária de quatro a dezessete anos de idade, pela Emenda Constitucional $n^{\circ} .59$ (BRASIL, 2009).

A ampliação da escolarização obrigatória determinada na esfera da norma constitucional se dá de forma tal que a repetição de erros cometidos no passado recente parece inevitável, qual seja: uma expansão acelerada e improvisada, sem que as condições de sua efetivação sejam garantidas aos entes federativos diretamente responsáveis (municípios e estados), no curto prazo fixado (ano 2016).

É importante lembrar que o impulso expansionista do ensino obrigatório (ensino fundamental) no contexto do regime militar autoritário (1964-1984) gerou um cenário de coexistência de expressiva cobertura populacional e importantes ganhos no acesso ao ensino com escolas cujo caráter público democrático não se concretizou (BEISIEGEL, 1993).

Com essa herança educacional, a institucionalidade gerada com o fim daquele regime declarou a educação como direito de todos e como elemento da proteção integral da criança e do adolescente, determinando a qualificação e universalização do ensino, com prioridade ao fundamental, conforme antes mencionado. 
Sinalizados desde o contexto internacional, os desafios educacionais brasileiros passaram a ser enfrentados com medidas descentralizadoras e de modernização da gestão dos sistemas de ensino e das suas escolas, uma vez que elas foram consideradas imprescindíveis à eficiência e eficácia do processo de escolarização, num país que persegue maior inserção competitiva no cenário internacional e que, internamente, tem de se tornar capaz de reduzir desigualdades de toda ordem.

Os avanços verificados na educação brasileira (OLIVEIRA, 2007) não mudaram significativamente a escola que Beisiegel (1993) apontou como imprescindivel e cuja natureza excludente foi salientada por muitos, entre os quais Arroyo (2000).

Vieira (2004) avaliou que a consecução dos dispositivos constitucionais se deu consoante a uma concepção minimalista de direito social, não logrando resolver as situações de restrição e negação do direito da população ao acesso e atendimento, com qualidade, em todas as etapas da educação básica. As taxas de analfabetismo da população adolescente e jovem, bem como os índices de não conclusão do ensino obrigatório, são indicadores ilustrativos entre outros.

Mesmo assim, a recente ampliação da cobertura populacional do estatuto do direito público subjetivo à educação não deixa de ser uma importante conquista, na esfera legal, que, sobretudo, redimensiona os desafios educacionais para municípios e estados.

Porém, é preciso atentar para o fato de que um dos maiores desafios para a efetivação do direito ao ensino obrigatório advém da heterogeneidade da sociedade brasileira, marcada principalmente pelas desigualdades regionais. Estas se expressam sobremaneira no âmbito municipal, para onde concorrem as demandas sociais e onde se dá a realização da política educacional.

Abrúcio (2006, p. 97) afirma que "o bom desempenho" dos municipios brasileiros é obstaculizado com

[...] a desigualdade de condições econômicas e administrativas, o discurso do 'municipalismo autárquico', a metropolização acelerada, os resquícios ainda existentes tanto de uma cultura política quanto de instituições que dificultam a accountability democrática e o padrão das relações intergovernamentais.

Nesse contexto, os municipios com população menor que um milhão e maior que trezentos mil habitantes apresentam $40,5 \%$ das suas receitas como próprias e 59,5\% delas como receitas de transferências; os municípios com população menor que trezentos mil e maior que cinquenta mil arrecadam de receitas próprias $31,4 \%$ e recebem de transferências $68,6 \%$; e os municipios 
com população menor que cinquenta mil habitantes arrecadam $15,5 \%$ de receitas próprias e $84,5 \%$ são transferências intergovernamentais. (BRASIL, 2008). Os municípios que fazem parte desta pesquisa apresentam dados populacionais de acordo com o mencionado acima, como mostra a tabela 01.

De fato, a grande maioria dos municípios brasileiros sobrevive financeiramente das transferências intergovernamentais. A baixa capacidade de arrecadação de grande número deles restringe investimentos próprios na educação, de modo que a vinculação constitucional de recursos não se constitui solução suficiente, assim como os arranjos que propiciaram a gestão do financiamento instrumentada por fundos como o Fundo de Manutenção e Desenvolvimento do Ensino fundamental e de Valorização do Magistério (Fundef) ${ }^{2}$ e o Fundo de Manutenção e Desenvolvimento da Educação Básica e de Valorização dos Profissionais da Educação (Fundeb)³.

Em face dessa situação, a estratégia de suplência da União, adotada no âmbito do Plano de Desenvolvimento da Educação (PDE) (BRASIL, 2007c), ainda é recente para qualquer avaliação, mas está patente que depende da capacidade de "controle remoto" da União e de como se estabelecem e sustentam as intrincadas relações intergovernamentais. Nestas, o conflito político e administrativo entre "mais centro" e "menos centro" toma diferentes formas, demandando da coordenação federativa esforços imensos de vigilância e controles continuados, que consomem escassos recursos para a área e engajam as forças sociais centripetas. $A$ isso soma 0 fato de que a frequentemente referida "parceria da sociedade" no controle da qualidade do ensino tem sido mínima, fraca, pontual e esporádica.

Os desafios educacionais são, portanto, enormes e complexos. Na sequência, buscamos vislumbrá-los de um conjunto de casos municipais situados num estado com pouca expressão nacional (econômica, política, cultural, administrativa). Situação em que se encontram muitos estados brasileiros, ainda que em diferentes graus.

\section{A efetivação do direito à educação em municípios sul-mato-grossenses}

Quatro dos municípios observados são de pequeno porte, registrando em 2010 uma população inferior a 35 mil habitantes: um deles possui 103.703 habitantes e o maior do conjunto, o de Campo Grande, soma 786.797 pessoas residentes (IBGE, 2010).

2 O Fundef foi instituído pela Lei $\mathrm{n}^{\circ}$. 9.424 (apud BRASIL, 2001), e regulamentou a Emenda Constitucional $n^{\circ} .14$ (BRASIL, 1996). O Fundef subvinculou 15\% das receitas para Manutenção e Desenvolvimento do Ensino tão somente para o ensino fundamental.

3 O Fundeb foi instituído pela Lei $\mathrm{n}^{\circ} .11 .494$ (BRASIL, 2007b) e regulamentou a Emenda Constitucional $n^{\circ} .53$ (BRASIL, 2006a). O Fundeb subvinculou 20\% das receitas para Manutenção e Desenvolvimento do Ensino para a educação básica. 
Com exceção deste último, os municipios sobrevivem, financeiramente, das transferências intergovernamentais e estas representam um total de $84,5 \%$ das suas receitas, conforme dados de 2008 do Tesouro Nacional (BRASIL, 2008).

Cabe lembrar que, quando os municípios se organizam para implantar na esfera local a política educacional, dentre as outras políticas sociais, seu gasto com tal processo está sempre além do planejado, onerando de imediato as finanças municipais e reduzindo a sua capacidade operativa. Logo, os desafios educacionais são enormes para a maioria daqueles municípios, muito mais quando os processos de descentralização e municipalização tornam fundamental a atuação local para a efetivação do direito à educação.

Mas, conforme antes mencionado, trata-se aqui de analisar a dimensão legislativa e a administrativa da atuação municipal na efetivação do direito público subjetivo à educação.

\section{A dimensão legislativa}

A averiguação das contribuições do Legislativo municipal para a efetivação do direito público subjetivo à educação no municipio se deve não só ao fato de que the compete legislar complementarmente, mas, também, porque as normas constitucionais e legais nacionais não esgotam a possibilidade de criação/inventividade nos âmbitos subnacionais. Há possibilidades que não parecem dispensáveis diante dos desafios educacionais a enfrentar e a escassez de recursos já foi mencionada.

Em primeiro lugar, investigamos o conteúdo das leis orgânicas municipais e de suas emendas até 2007, buscando disposições pró-efetivação do direito à educação, em particular do ensino fundamental. Disposições essas que fossem de iniciativa municipal e representassem acréscimos ou detalhamentos às determinações constitucionais e ordinárias da União. Em outras palavras, que expressassem proposições locais diante do desafio de efetivar tal direito.

Cabe lembrar, com o auxílio de Duarte (2006), que muitas das normas jurídicas para a educação apresentam alto grau de generalidade, sendo princípios e não regras. Como princípios exigem que se faça algo, tanto mais quanto possivel diante dos limites concretos encontrados. Eles apontam a direção, mas não determinam a decisão possivel. Entendemos que demandam de cada contexto decisões sobre possibilidades e alternativas que podem ser sinalizadas pela legislação complementar.

A análise de peças normativas dos municípios mostrou que são escassas as disposições para a educação que indicam um esforço nesse sentido. Não sem algum grau de frouxidão de critérios, conseguimos classificar as tentativas municipais em três categorias: acesso, aparelhamento e formulação de políticas educacionais. Seguem sucintamente: 
- Acesso - mobilização social, aplicação de recursos próprios na concessão de bolsas e prioritariamente na construção de estabelecimentos públicos para suprir faltas de vagas, convênios para atendimento de alunos com necessidades especiais, assistência educacional financiada com recursos próprios.

- Aparelhamento - criação do Conselho Municipal de Educação e do Conselho Municipal dos Direitos da Criança e do Adolescente.

- Formulação de políticas - menção apenas à participação da sociedade nesse processo.

$\mathrm{Na}$ categoria acesso, a lógica determinante consiste, em alguns casos, em operar dentro dos padrões dos programas de "renda mínima", que nem sempre agregam renda aos usuários, mas garantem a frequência do aluno à escola.

Quanto às categorias aparelhamento e formulação de políticas, podemos observar que a participação social requerida quando da criação de conselhos de acompanhamento e controle da política educacional vai ao encontro dos modelos de flexibilidade da administração pública, da descentralização financeira exequivel no orçamento público e que, como observou Oliveira (2005, p. 765), "[...] apelam para as noções de autonomia e participação oriundas dos movimentos reivindicativos, ainda que os envolvidos sejam, a rigor, meros contribuintes ou assistidos".

Verificamos que a inventividade normativa está praticamente ausente no produto do processo legislativo municipal, indicando baixa contribuição dessa esfera na sinalização de possibilidades e alternativas, bem como na fixação de parâmetros para a efetivação do direito à educação pela gestão local, inclusive na elaboração do Plano Municipal de Educação, excetuados os casos de Campo Grande e Corumbá.

Se, no contexto da democracia política, o produto da elaboração legislativa representa a solução dada para reclamos e embates sociais, o quadro encontrado sugere que a efetivação do direito à educação não se constituiu objeto privilegiado de tais reclamos e embates nos municípios considerados.

\section{A dimensão administrativa}

Procuramos também saber que medidas as Secretarias Municipais de Educação (SEMEs) e os Conselhos Municipais de Educação (CMEs) têm adotado visando à efetivação do direito ao ensino fundamental em sua jurisdição, considerando especificamente o desafio do acesso e gratuidade, da igualdade de oportunidades, da permanência e sucesso escolar e do padrão de qualidade do ensino. Utilizamos questionários impressos e em meio eletrônico para obter as informações com profissionais das SEMEs responsáveis pelo ensino fundamental e com os presidentes dos CMEs.

Com relação a acesso e gratuidade, duas Secretarias mencionaram como medidas "o levantamento da demanda", e três delas, "a matrícula de todos". Com apenas uma menção 
apareceram as seguintes medidas: chamada pública, gratuidade total, respeito à legislação vigente, transporte, merenda de qualidade, ampliação e construção de escolas.

Não apareceram, entre outras, iniciativas que indiquem empenho na avaliação diagnóstica, nos estudos projetivos, na definição de estratégias e instrumentos próprios para o monitoramento de metas, na articulação de politicas de promoção, proteção e reposição do direito ao acesso à educação básica.

A situação não é muito diferente na esfera de atuação dos CMEs. Com apenas uma menção aparecem iniciativas como avaliação dos prédios (localização, acessibilidade, higiene, conforto e segurança), fiscalização do cumprimento da legislação de transporte escolar, levantamento da demanda atendida, parceria (não especificada) com a Secretaria Estadual de Educação (SED) e estabelecimento de normas para o ensino fundamental de nove anos.

No que diz respeito à igualdade de oportunidades, as SEMEs foram quase unânimes em apontar o acolhimento universal dos alunos como estratégia de sua intervenção. Medidas relativas à qualificação da merenda escolar, ao oferecimento de transporte, à adoção de uniforme escolar, ao fornecimento de material escolar e ao atendimento/acompanhamento de alunos com necessidades educacionais especiais receberam uma menção da parte dos informantes.

Em que consiste efetivamente o acolhimento mencionado, o que representa no tratamento das desigualdades, diferenças e diversidades não foi possível aquilatar.

Os CMEs, por sua vez, mencionam atenção ao objetivo do ensino fundamental, política democrática cidadã, parceria com a SED (não especificada) e fixação de normas para inclusão de alunos com necessidades educacionais especiais. Cada uma das iniciativas recebeu também apenas uma menção e não ficou claro o que se fez e se obteve com isso.

Os aspectos relativos à permanência e sucesso escolar as iniciativas mencionadas pelas SEMEs são pontuais e se referem ou à oferta de condições favoráveis (conservação do prédio, transporte, materiais escolares), ou ao acompanhamento do escolar (freqüência, rendimento e atendimento especializado), ou à articulação com as famílias e comunidade (reuniões, visitas às famílias, participação da comunidade na escola), ou ao incentivo ao gosto pelo estudo.

Os CMEs, por sua vez, mencionaram iniciativas normativas, de parceria com a SED e adaptações do ensino para a população do campo. Tais adaptações normativas procuram combinar ações do programa "Transporte Escolar Rural" (Transrural) com ações de um calendário escolar adequado ao trabalho do campo. 
Os dados coletados revelaram que, na maioria dos municípios observados, as políticas de promoção, proteção, defesa e reposição do direito à educação não estão sistemática e articuladamente delineadas. Não são identificáveis estratégias, mecanismos e instrumentos para o enfrentamento da "cultura de exclusão".

Entretanto, a taxa de distorção idade/conclusão no ensino fundamental municipal das localidades em foco (Tabela 1) pode ser reveladora.

Tabela 1: Distorção idade/conclusão do ensino fundamental municipal (2001 e 2005) em municípios selecionados.

\begin{tabular}{l|c|c}
\hline Unidade territorial & \multicolumn{2}{|c}{ Taxa de distorção idade/conclusão } \\
\hline Amambai & 2001 & 2005 \\
\hline Bela Vista & 49,1 & 60,5 \\
\hline Campo Grande & 50,6 & 65,5 \\
\hline Corumbá & 54,5 & 60,9 \\
\hline Nova Alvorada do Sul & 52,3 & 57,1 \\
\hline Paranhos & 56,9 & 56,7 \\
\hline
\end{tabular}

Fonte: Inep (2010).

A taxa de distorção idade/conclusão no ensino fundamental municipal cresceu em todos os municípios no período 2001-2005, exceto em Nova Alvorada do Sul. Somente as taxas de reprovação e de abandono não explicam esse crescimento, ainda que continuem expressivas e tenham aumentado. Deve-se também à reposição do direito ao ensino fundamental para parcelas da população acima de 14 anos.

Quanto a tal reposição, as SEMEs informam, como iniciativas na educação de jovens e adultos (EJA), a definição de horário, de método e didática específicos, além da aceleração de estudos. Os CMEs mencionaram iniciativas de estudo para implantação do EJA rural, elaboração de norma específica para o ensino noturno, bem como normas para cursos e exames.

A igualdade de oportunidade depende que o dito "acolhimento" no ensino fundamental se dê de modo a assegurar a sua qualidade.

Embora baseado numa concepção restrita de qualidade em educação, o Índice de Desenvolvimento da Educação Básica (Ideb) nos mostra um cenário de desafios à investigação e à intervenção pública (Tabela 2). Basicamente, conforme esclarece 0 próprio Inep (2007, 2010), o Ideb sintetiza a qualidade de dois indicadores: fluxo (aprovação) e desempenho cognitivo dos alunos em componentes avaliados (Português, Leitura e Matemática: cálculo e raciocínio). 
Tabela 2: Índice de desenvolvimento do ensino fundamental em redes escolares municipais sul-mato-grossenses selecionadas (2005 e 2007).

\begin{tabular}{l|c|c|c|c}
\hline Unidade territorial & \multicolumn{2}{|c|}{ Anos iniciais } & \multicolumn{2}{c}{ Anos finais } \\
\hline Amambai & 2005 & 2007 & 2005 & 2007 \\
\hline Bela Vista & 2,9 & 3,9 & 3,2 & 3,6 \\
\hline Campo Grande & 2,7 & 3,5 & - & 3,7 \\
\hline Corumbá & 4,2 & 5,1 & 3,7 & 4,5 \\
\hline Nova Alvorada do Sul & 3,1 & 3,4 & 2,7 & 3,0 \\
\hline Paranhos & 3,2 & 3,9 & 3,5 & 3,7 \\
\hline MS - estadual & 3,2 & 4,3 & 3,7 & 3,7 \\
\hline BR - municipal & 3,4 & 4,0 & 2,9 & 3,5 \\
\hline BR - pública & 3,6 & 4,0 & 3,1 & 3,4 \\
\hline Fonte: & 4,0 & 3,2 & 3,5 \\
\hline
\end{tabular}

Fonte: Inep (2007).

No conjunto de municípios observados, a situação mais positiva é a de Campo Grande, que obteve Ideb superior aos de Mato Grosso do Sul (MS estadual) e do Brasil (rede municipal e redes públicas), tanto nos anos iniciais como nos finais, tanto em 2005 como em 2007. Apresenta os mais elevados Índices no conjunto menos em 2005, quando empata com Paranhos nos anos finais do ensino fundamental. Apresenta também a maior variação no período 20052007 nos anos finais (INEP, 2007).

Somente Campo Grande e Paranhos apresentam Ideb nos anos iniciais superiores ao MS e Brasil. Paranhos se destacou com a maior variação 2005-2007 nos anos iniciais (de 1,1), mas ficou estável nos anos finais. Esse município é o que apresentava, no ano 2000, os menores índices de desenvolvimento humano e a maior taxa de analfabetismo do conjunto observado (igual à verificada no Brasil). Já o município de Campo Grande apresentava os melhores índices de desenvolvimento humano e menor taxa de analfabetismo no conjunto (INEP, 2007).

Corumbá apresentou em 2007 os menores Idebs nos anos iniciais e finais, sendo que as variações no período 2005-2007 foram pequenas $(0,3)$ melhores somente que nos anos finais em Nova Alvorada do Sul $(0,2)$. Nestes dois municípios se encontram os menores resultados. Mas, Corumbá apresenta indices de desenvolvimento humano maiores que vários outros municipios do conjunto e superior ao do Brasil, sendo a sua taxa de analfabetismo menor que a do pais. Nova Alvorada do Sul tem melhores indices de desenvolvimento humano do que Paranhos, mas que ficam entre os mais baixos do conjunto, tendo, no entanto, uma das mais baixas taxas de analfabetismo, menor que a do MS (INEP, 2007). 
Esses dados ilustram a afirmação anteriormente feita acerca de que a educação municipal é múltipla e díspar. Isso torna ainda mais decisiva a política e gestão locais da efetivação do direito à educação, de modo a que igualdade de oportunidade, permanência e sucesso escolar sejam decorrências da qualificação do ensino.

Procuramos saber que iniciativas foram tomadas visando à qualificação do ensino obrigatório. As SEMEs enumeraram medidas de orientação e formação (especifica, em serviço) voltadas para diretores de escolas e professores, de monitoramento das ações desenvolvidas nas escolas e de avaliação externa. Os CMEs mencionaram iniciativas normativas, de parceria com a SED (sem esclarecer o seu objeto) e a avaliação externa.

Focando a produção da regulamentação - que entendemos ser possibilidade de complementação da legislação que está ao alcance dos agentes mais próximos do fazer educação - procuramos saber com as SEMEs e os CMEs quais mecanismos pró-efetivação do direito à educação foram introduzidos nos regimentos das escolas municipais.

No tocante à facilitação do acesso e permanência foram mencionadas pelas SEMEs a oferta de educação especial e informática, acesso a conhecimento universal, condições fisicas e materiais adequadas ao aluno com necessidades educacionais especiais, condições favoráveis de transporte, material e merenda escolar. Os CMEs mencionaram estímulo à frequência escolar, educação especial e informática.

Com relação à promoção da igualdade de oportunidades na escola, as SEMEs informaram que teriam sido incluídos nos regimentos escolares mecanismos relativos à matrícula universal, elaboração de projeto pedagógico, aceleração de estudos, classificação e reclassificação, acompanhamento clínico para alunos com dificuldades, educação especial, condições materiais e atividades adequadas às fases de desenvolvimento da criança. Os CMEs mencionaram mecanismos relativos às diferenças individuais, consideração da diversidade cultural, matrícula universal.

As SEMEs afirmam que foram introduzidos, nos regimentos escolares, mecanismos de promoção do êxito (ou sucesso) escolar como recuperação, sala de reforço, conselho de classe, exame final, reclassificação, premiação de docentes, atividades culturais e esportivas, materiais escolares, aprovação para a sérsubsequente, avaliação por competência, avaliação global, contínua e cumulativa do desempenho por meio de diferentes técnicas e instrumentos.

Segundo os CMEs, os mecanismos introduzidos foram avaliação global com respeito à individualidade, recuperação, conselho de classe, exame final, reclassificação. Tais mecanismos receberam uma única menção, de modo que não são comuns aos municípios. 
No conjunto, observamos que o monitoramento e a avaliação da efetivação do direito à educação não catalisam esforços da gestão local, embora sejam por vezes referidos. Assim também a busca de alternativas às indicações constantes nas normas gerais emanadas da União.

Não é, portanto, na administração da rede escolar que se encontram indícios de inventividade e autonomia criativa.

\section{Considerações finais}

Constatamos que, para a realização da sua agenda de política educacional, a gestão local, nos casos observados, padece de colocar em pauta a sua autonomia relativa no que concerne ao efetivo exercicio de garantir o direito à educação, à medida que, muito mais do que legislar, considerando as especificidades locais, ela tem se pautado pelas regulamentações nacionais.

A "falta" de capacidade inventiva e autônoma dos municípios repercute no processo político de descentralização, na medida em que eles deixam de conquistar poder decisório tanto na regulamentação jurídica (no que Ihes compete) como no comando administrativo direto da educação escolar. Desse modo, reforça-se o poder do governo central na gestão educacional municipal, em lugar de avançar na conquista de maior autonomia.

Tal avanço requer enfrentamento de importantes obstáculos, como: a pouca margem de manobra para iniciativas específicas postas pelas regras constitucionais sobre competências, recursos e políticas públicas (SOUZA, 2006); a exigência do Supremo Tribunal Federal (STF) de que as leis subnacionais reflitam os dispositivos federais, o que concorre para o estabelecimento de hierarquia de tais normas (SOUZA, 2006); e a escassez de recursos próprios devida à baixa capacidade tributária local (ABRÚCIO, 2006).

Em que pesem esses obstáculos, cabe ponderar a respeito de quão pouco tem prosperado a autonomia republicana dos governos locais na área da educação e, com ela, as possibilidades de busca de soluções criativas e vinculadas às peculiaridades locais, para responder ao imperativo da efetivação do direito à educação.

Isso opera em prejuizo da maior democratização do poder público como instrumento para fazer frente à concentração de recursos no nível central.

Analisando o conjunto de dados, percebemos a necessidade de fazer surgir na esfera municipal capacidades político-institucionais e técnico-administrativas para se lidar conseqüentemente com a efetivação do direito à educação.

Adotando a ótica analítica de Abrúcio (2006, p. 89), entendemos que isso requer engajamento tanto do governo central quanto dos governos subnacionais, sendo 
que todos precisam "[...] desenvolver instrumentos e mesmo uma cultura política vinculados às relações intergovernamentais, em particular no caso do governo central, em razão de seu papel necessariamente coordenador". Tanto mais que na organização federativa o princípio da soberania compartilhada implica garantia de autonomia e, ao mesmo tempo, interdependência entre os governos.

Na esfera das políticas públicas, a coordenação federativa requer um modus operandi cooperativo que permita o compartilhamento de objetivos e tarefas, tendo como meio processos centralizadores, mas o entrelaçamento dos niveis de governo (ABRÚCIO, 2006). Requer, também, da gestão local iniciativas que permitam a construção de um sistema articulado de proteção ao direito à educação instrumentado por uma prática de autoavaliação responsável e consequente.

\section{Referências}

ABRUCIO, F. L. Para além da descentralização: os desafios da coordenação federativa no Brasil. In: FLEURY, S. Democracia, descentralização e desenvolvimento: Brasil e Espanha. Rio de Janeiro: Ed. FGV, 2006. p. 76-125.

ANDRADE, L. A. 0 município na política brasileira: revisitando coronelismo, enxada e voto. In: AVELAR, L.; CINTRA, A. O. (Org.). Sistema político brasileiro: uma introdução. Rio de Janeiro: Fundação Konrad-Adenauer-Stiftung; São Paulo: Fundação UNESP Ed., 2004. p. 205-218.

ARROYO, M. G. Fracasso/sucesso: um pesadelo que perturba nossos sonhos. Em Aberto, Brasília, DF, v. 17, n. 71, p. 33-40, jan. 2000.

BEISIEGEL, C. R. Considerações a propósito de um projeto educacional. São Paulo Em Perspectiva, São Paulo, v. 7, n. 1, p. 38-49, jan./mar. 1993.

BRASIL. Constituição (1988). Constituição da República Federativa do Brasil. Brasília, DF: Senado, 1988.

. Decreto no 6.094, de 24 de abril de 2007. Dispõe sobre a implementação do Plano de Metas Compromisso Todos pela Educação, pela União Federal, em regime de colaboração com Municípios, Distrito Federal e Estados, e a participação das famílias e da comunidade, mediante programas e ações de assistência técnica e financeira, visando a mobilização social pela melhoria da qualidade da educação básica. Diário Oficial da União, Brasilia, DF, 2007a. Disponivel em:<http://www.planalto.gov.br/ccivil_03/_Ato2007-2010/2007/ Decreto/D6094.htm>. Acesso em: 3 maio 2011. 
BRASIL. Emenda Constitucional no. 14, de 12 de setembro de 1996. Modifica os art. 34, 208, 211 e 212 da Constituição Federal e dá nova redação ao art. 60 do Ato de disposições constitucionais transitórias. Diário Oficial da União, Brasília, DF, 13 de set. 1996.

. Emenda Constitucional $n^{\circ}$. 53, de 19 de dezembro de 2006. Dá nova redação aos arts. 70, 23, 30, 206, 208, 211 e 212 da Constituição Federal e ao art. 60 do Ato das Disposições Constitucionais Transitórias. Diário Oficial da União, Brasília, DF, 2006a. Disponivel em: <http:www.planalto.gov.br/ccivil_03/ constituição/emendas/ emc/emc53.htm>. Acesso em: 5 maio 2011.

. Emenda Constitucional n ${ }^{\circ} 59$, de 11 de novembro de 2009. Acrescenta $\S 3^{\circ}$ ao art. 76 do Ato das Disposições Constitucionais Transitórias para reduzir, anualmente, a partir do exercício de 2009... Diário Oficial da União, Brasília, DF, 11 nov. 2009.

. Câmara dos Deputados. Comissão de Educação, Cultura e Desporto. Coordenação de Publicações. LDB \&t Lei do Fundef. Brasília, DF, 2001.

. Lei $n^{\circ} .11 .114$ de 16 de maio de 2005. Altera os artigos 06, 30, 32 e 87 da Lei no 9.394, de 20 de dezembro de 1996, com o objetivo de tornar obrigatório o início do ensino fundamental aos seis anos de idade. Diário Oficial da Uniõo, Brasília, DF, 17 maio 2005.

. Lei nº. 11.274, de 6 de fevereiro de 2006. Altera a redação dos artigos 29, 30, 32 e 87 da Lei $n^{\circ} 9.394$, de 20 de dezembro de 1996, que estabelece as diretrizes e bases da educação nacional, dispondo sobre a duração de nove anos para o ensino fundamental, com matrícula obrigatória a partir dos seis anos de idade. Diário Oficial da União, Brasilia, DF, 7 fev. $2006 b$.

. Lei $n^{0} .11 .494$, de 20 de junho de 2007. Regulamenta o Fundo de Manutenção e Desenvolvimento da Educação Básica e de Valorização dos Profissionais da Educação - FUNDEB, de que trata o art. 60 do Ato das Disposições Constitucionais Transitórias; e dá outras providências. Diário Oficial da União, Brasilia, DF, 2007b. Disponivel em: <http://www.planalto.gov.br/ ccivil_03/_Ato20072010/2007/Lei/L11738.htm>. Acesso em: 5 maio 2011.

Ministério da Educação. O Plano de Desenvolvimento da Educação: razões, princípios e programas. Brasília, DF, 2007c.

BRASIL. Ministério da Fazenda. Tesouro Nacional. Perfil e evolução das finanças municipais (1998-2007). Brasilia, DF, out. 2008. Disponivel em: <http:// www.tesouronacional.gov.br >. Acesso em: 4 maio 2011. 
CONFERÊNCIA MUNDIAL SOBRE DIREITOS HUMANOS, 2., 1993, Viena.

Declaração e Programa de Ação de Viena. Viena: Nações Unidas, 1993. Disponível em: <http://www.dhnet.org.br/direitos/anthist/viena/declaracao_viena.htm>. Acesso em: 3 maio 2011.

CONFERÊNCIA NACIONAL DE EDUCAÇÃO PARA TODOS, 1994, Brasilia; SIMPÓSIO NACIONAL DE EDUCAÇÃO INFANTIL, 1., 1994, Brasília. Anais... Brasilia, DF: MEC, SEF, DPE, COEDI, 1994.

DALE, R. Globalização e educação: demonstrando a existência de uma "cultura educacional mundial comum" ou localizando uma "agenda globalmente estruturada para a educação"? Educação, Sociedade \&t Culturas, n. 16, p. 133-169, 2001.

DIGIÁCOMO, M. J. Instrumentos jurídicos para garantia do direito à educação. In: LIBERATI, W. D. (Org.). Direito à educação: uma questão de justiça. São Paulo: Malheiros, 2004. p. 273-375.

DUARTE, C. S. Direito público subjetivo e políticas educacionais. São Paulo em Perspectiva, São Paulo, v. 18, n. 2, p. 113-118, 2004.

. A educação como um direito fundamental de natureza social. Educação \& Sociedade, Campinas, SP, v. 28, n. 100, p. 691-713, out. 2007. Especial.

. Reflexões sobre a justiciabilidade do direito à educação no Brasil. In: HADDAD, S.; GRACIANO, M. (Org.). A educação entre os direitos humanos. Campinas, SP: Autores Associados, 2006. p. 127-153.

HELD, D.; McGREW, A. Prós e contras da globalização. Rio de Janeiro: Zahar, 2001.

HORTA, J. S. B. Direito à educação e obrigatoriedade escolar. Cadernos de Pesquisa, São Paulo, n. 104, p. 5-34, jul. 1998.

IBGE. Sinopse do Censo Demográfico 2010. Brasília, DF, 2010. <Disponível em: <http://www.censo2010.ibge.gov.br/sinopse/>. Acesso em: 3 maio 2011.

INEP. Edudata Brasil. Brasilia, DF, 2010. Disponível em: <http:// www.edudatabrasil.inep.gov.br/>. Acesso em: 3 maio 2011.

INEP. Índice de Desenvolvimento da Educação Básica: metas e resultados. Instituto Nacional de Estudos e Pesquisas Educacionais. Brasília, DF, 2007. Disponivel em: <http://sistemasideb.inep.gov.br/resultado/>. Acesso em: 03 mai. 2011. 
MARQUES, M. T. S. Sistema de garantia de direitos da infância e da juventude. In: LIBERATI, W. D. (Org.). Direito à educação: uma questão de justiça. São Paulo: Malheiros, 2004.

MONTEIRO, A. R. Algumas idéias para pensar e lutar pelo direito à educação, para humanizar a globalização. In: FORUM MUNDIAL DE EDUCAÇÃO, 2., 2003, Porto Alegre. Trabalhos apresentados... Porto Alegre, 2003a. Disponivel em: <http://noite.wordpress.com/2009/12/07/a-humanizando-a-globalizacao/>. Acesso em: 28 jul. 2006.

. 0 pão do direito à educação... Educação \& Sociedade, Campinas, SP, v. 24 , n. 84 , p. 763-789, set. 2003 b.

NACIONES UNIDAS. Consejo Econômico y Social. Comisión de Derechos Humanos. Los derechos económicos, sociales y culturales: el derecho a la educación: Informe presentado por Katarina Tomasevski, Relatora Especial sobre el derecho a la educación, 60 período de sesiones. E/CN.4/2004/45, 25 enero 2004.

Disponivel em: <http://www.unhchr.ch/Huridocda/Huridoca.nsf/0/ 4ae57c3d96fddd45c1256e46003c3bd4?0pendocument>. Acesso em: 16 nov. 2006.

NAÇÕES UNIDAS. Declaração do Milênio: Cimeira do Milénio. Nova lorque, 2000. Disponivel em: <http://www.pnud.org.br/odm/\#>. Acesso em: 3 maio 2011.

OECD. Education at a Glance 2009: OECD Indicators. Paris, 2009.

OLIVEIRA, D. A. Regulação das políticas educacionais na América Latina e suas conseqüências para os trabalhadores docentes. Educação \&t Sociedade, Campinas, SP, v. 26, n. 92, p. 753-775, out. 2005. Especial.

OLIVEIRA, R. P. Da universalização do ensino fundamental ao desafio da qualidade: uma análise histórica. Educação \&t Sociedade, v. 28, n. 100, p. 661690, out. 2007. Especial.

OLIVEIRA, R. P. Educação e cidadania: o direito à educação na Constituição de 1988 da República Federativa do Brasil. 1995. 152 f. Tese (Doutorado)- Faculdade de Educação, Universidade de São Paulo, São Paulo, 1995.

SOUZA, C. Desenho constitucional, instituições federativas e relações intergovernamentais no Brasil pós-1988. In: FLEURY, S. Democracia, descentralização e desenvolvimento: Brasil e Espanha. Rio de Janeiro: Editora FGV, 2006. p. 186-211. 
TOMASEVSKI, K. Por que a educação não é gratuita?. In: HADDAD, S.; GRACIANO, M. (Org.). A educação entre os direitos humanos. Campinas, SP: Autores Associados, 2006. p. 61-91.

TORRES, R. M. Educação para todos: a tarefa por fazer. Porto Alegre: ARTMED, 2001.

UNESCO (Portugal). Comissão Nacional. Programa de Educação para Todos. [Lisboa?]: Unesco, [199?]. Disponivel em: <http://www.unesco.pt/cgi-bin/ educacao/temas/edu_tema.php?t=2>. Acesso em: 3 maio 2011.

. Educação de qualidade para todos: um assunto de direitos humanos. Brasília, DF: UNESCO, OREALC, 2007.

VIEIRA, E. Os direitos e a política social. São Paulo: Cortez, 2004.

Recebido em: 01/04/2010

Aceito para publicação em: 17/05/2011 